EXPERIMENTAL STUDY

\title{
Thyrotropin regulates tyrosine sulfation of thyroglobulin
}

\author{
Marie-Christine Nlend, David Cauvi, Nicole Venot, Sylvie Desruisseau ${ }^{1}$ and Odile Chabaud \\ INSERM U38, Faculté de Médecine, Université de la Méditerranée, 27 bd J. Moulin, 13385 Marseille, Cedex 05, France and ${ }^{1}$ INSERM, CJF 93-11, \\ Faculté de Médecine Nord, Université de la Méditerranée, bd P. Dramard, 13916 Marseille Cedex 20, France
}

(Correspondence should be addressed to O Chabaud)

\begin{abstract}
Objective: To study the regulation of thyroglobulin sulfation by thyrotropin (TSH) and iodide. Sulfation, a widespread post-translational modification of proteins, is involved in various biological activities. Thyroglobulin has been reported to be sulfated but, to date, the role of sulfate residues in the metabolism and function of thyroglobulin is not known; moreover, the regulation of thyroglobulin sulfation has not been yet investigated.

Methods: The effect of TSH on thyroglobulin sulfation was studied in porcine thyroid cells cultured on porous collagen-coated filters. Cells cultured with or without TSH and with or without iodide (KI) were incubated for 4 days with radioactive sulfate. The specific radioactivity of thyroglobulin subunit $(330 \mathrm{kDa})$ was determined from apical media analyzed by electrophoresis. Enzymatic hydrolysates of the purified thyroglobulin were separated by oligosaccharide affinity chromatography and thin-layer chromatography; alkaline hydrolysates were analyzed only by thin-layer chromatography.

Results: Thyroglobulin secreted by TSH-stimulated cells incorporated about twofold less radioactive sulfate. Iodide slightly modified this incorporation. Enzymatic hydrolysates of purified thyroglobulin showed sulfate residues bound essentially to complex oligosaccharide units. Alkaline hydrolysis was necessary to release all sulfated amino acids (tyrosine and serine). In the absence of TSH the proportion of tyrosine sulfate was dramatically increased: $24 \%$ compared with $7 \%(+\mathrm{KI})$ or $5 \%(-\mathrm{KI})$. The ratio of specific radioactivity of thyroglobulin to the specific radioactivity of intracellular inorganic sulfate (determined in each culture condition) gave the number of sulfated residues incorporated: 46 ( $-\mathrm{TSH}$ ) and $31(+\mathrm{TSH})$ per mol thyroglobulin. From this distribution, we deduced the number of residues bound to complex oligosaccharide units and to tyrosine. Thus TSH decreased the number of sulfate residues on tyrosine from 11 to 2 per mol thyroglobulin.

Conclusions: TSH regulates the binding of sulfate groups to tyrosine residues. Iodide exerts a slight control over this process.
\end{abstract}

European Journal of Endocrinology 141 61-69

\section{Introduction}

Sulfation is a late post-translational modification of proteins taking place in the trans-Golgi apparatus (1). Protein sulfation occurs in numerous glycoproteins, secreted (for reviews see $(2,3)$ ) or membrane-inserted (4). Sulfate residues are present on carbohydrate units (for review see (5)) and on some amino acids, especially tyrosine (2-4). The roles and functions of these sulfate residues differ: they are probably involved in the molecular conformations of proteins and in proteinprotein interactions, and they can have a role in the process of activation-deactivation of protein biological activities, particularly when they are bound to tyrosine molecules (6-9). However, the functions of sulfate residues on numerous proteins are not understood, and little has been reported on the regulation of sulfate binding. Protein sulfation is modified in pathological states (10), transformed cells (11), or hematopoietic tumor cell lines (12). Increased carbohydrate sulfation was observed on the bronchial mucins in cystic fibrosis (13) and on leukosialin $\mathrm{CD} 43$ in the murine $\mathrm{T}$ lymphoma line RDM-4 as compared with resting splenic T cells (14).

Sulfation of thyroglobulin, the glycoprotein precursor of thyroid hormones, occurs in the protein of groups from lower vertebrates to mammals (15). Sulfate residues are bound essentially to complex carbohydrate units of calf $(16,17)$, human $(16,18)$, and porcine $(19$, 20) thyroglobulin. Chondroitins are also sulfated, but are present only in human thyroglobulin (18). Contradictory results from studies of porcine thyroglobulin suggested that a large proportion of the sulfate residues are bound to tyrosine molecules, while the rest are linked to polymannose moieties $(15,21)$. In thyroid pathological states, alterations of thyroglobulin sulfation 
have been observed: human thyroglobulin from neoplastic thyroid tissue contained more sulfate residues bound to oligosacharide units $(22,23)$.

The role of sulfate residues in the metabolism of thyroglobulin and in its physiological function is not known. Recently, it was shown that, in Pendred syndrome (a congenital sensorineural hearing loss combined with goiter), gene mutations of a putative sulfate transporter occurred (24). This may suggest a relation between thyroid function and sulfate metabolism.

Until now, the dependence of thyroglobulin sulfation on thyrotropin (TSH) stimulation has not been investigated. We have now studied the regulation of sulfate incorporation into thyroglobulin by TSH and iodide, the proportion of sulfate residues bound to oligosaccharide units and to the polypeptide chain, and the effect of TSH and iodide on this distribution.

The experiments were carried out using thyroglobulin secreted by porcine thyroid cells cultured on porous collagen-coated filters. This culture system operates as 'an open thyroid follicle' in which the polarized organization is maintained as in vivo: nutrients, hormones, and other effectors have direct access to the basolateral membranes, and thyroglobulin is secreted into the apical compartment, corresponding to the colloid. Over many years, we have accumulated extensive data on this culture system, which simulates thyroid metabolism in vivo, up to the stage of secretion of thyroid hormones into the basal medium (unpublished results). We have shown that TSH controlled all the steps of thyroglobulin metabolism that we have studied: thyroglobulin expression and secretion (25-28), and two post-translational modifications, glycosylation $(29$, 30) and iodination (31).

In this paper, we demonstrate that, in our culture conditions, TSH downregulates thyroglobulin sulfation, particularly on tyrosines, and we propose some hypotheses on the basis of our findings.

\section{Materials and methods}

\section{Cell culture}

Epithelial cells were isolated from porcine thyroid glands and cultured on collagen-coated filters as described previously (25). Briefly, isolated cells suspended in phenol red-free Dulbecco's modified Eagle's medium (DMEM containing glucose $1 \mathrm{~g} / \mathrm{l}$, Gibco Brl, Cergy Pontoise, France) were seeded into the apical compartment of chambers. The same medium was placed outside the ring in the basal compartment. From day 4 , the basal medium was supplemented with $10 \%$ newborn calf serum (Biological Industries, Beth Haemek, Israel), when media were changed. On day 6, the tightness of the monolayer was examined (25) and only tight monolayers were kept. From day 6, $100 \mu \mathrm{U} / \mathrm{ml}$ TSH (b-TSH, Calbiochem, San Diego, CA, USA) was added or not to the basal medium. From day 8 , potassium iodide was or was not added daily to the basal medium in a $0.5 \mu \mathrm{mol} / \mathrm{l}$ final concentration (31). As described previously (31), the apical medium was exchanged for B-DMEM (a saline DMEM medium devoid of amino acids and vitamins). Later, basal medium was changed every 3 days, maintaining the same TSH concentration with or without daily addition of iodide, without changing apical medium. Until day 15 , the inorganic sulfate concentration was $0.8 \mathrm{mmol} / \mathrm{l}$ in the apical medium, and about $1.2 \mathrm{mmol} / \mathrm{l}$ in the basal medium. On day 15, apical and basal media were changed; apical medium included B-DMEM containing $50 \% \mathrm{MgSO}_{4}$ and $50 \% \mathrm{MgCl}_{2}$; in the basal medium, $\mathrm{MgSO}_{4}$ was entirely replaced by $\mathrm{MgCl}_{2}$. The final concentration of inorganic sulfate was $0.4 \mathrm{mmol} / \mathrm{l}$ in apical media and about $0.4 \mathrm{mmol} / \mathrm{l}$ in basal media, in which sulfate was probably contributed by serum, antibiotics, and vitamins. When it was present, the concentration of iodide was $10 \mu \mathrm{mol} / \mathrm{l}$ in apical medium and $0.6 \mu \mathrm{mol} / \mathrm{l}$ in basal medium. Cells were labeled with the radiolabeled precursor sulphur-35 as sulfate, in aqueous solution containing mostly potassium as cation (Amersham Corp., Little Chalfont, England, $1000 \mathrm{Ci}$ / $\mathrm{mmol}$ ) at a concentration of $70 \mu \mathrm{Ci} / \mathrm{ml}$ basal medium. Culture was maintained for 4 days, because it has been reported that at least 3 days of continuous secretion are required to achieve saturation of thyroglobulin with $\left[{ }^{35}\right.$ S $]$ sulfate (21). On day 19, apical media were collected.

\section{Thyroglobulin purification}

Apical media from each culture condition were pooled and the different thyroglobulins were purified on a BioGel A-5m (Bio-Rad, Ivry-sur-Seine, France) column $(2 \times 70 \mathrm{~cm})$ equilibrated with $0.01 \mathrm{~mol} / \mathrm{l}$ ammonium bicarbonate buffer, $\mathrm{pH}$ 7.4. The fractions containing radiolabeled thyroglobulin were collected, concentrated and kept at $-20^{\circ} \mathrm{C}$ until required for further analysis. Protein was evaluated by Micro BCA protein assay (Pierce, Rockford, IL, USA).

\section{Polyacrylamide gel electrophoresis}

Aliquots from apical media from each culture condition were denatured and reduced as described previously (29). Samples were analyzed by SDS-PAGE using a 5\% $(\mathrm{w} / \mathrm{v})$ polyacrylamide gel according to the technique of Laemmli (32). Gels were stained with Coomassie blue and dried. Then they were scanned (Macintosh Microtek MSF300 GS) and analyzed by an image-analyzing program (NIH 1.49) and thyroglobulin was quantitatively determined by integration of peaks through a thyroglobulin standard reference curve included in each analysis.

\section{Enzymatic digestions}

A portion of purified radioactive thyroglobulin from each culture condition was dissolved $(100 \mu \mathrm{g} / 100 \mu \mathrm{l})$ in 
a $0.06 \mathrm{~mol} / \mathrm{l}$ final concentration ammonium bicarbonate buffer, $\mathrm{pH} 7.9$, and the samples were digested for $48 \mathrm{~h}$ at $37^{\circ} \mathrm{C}$ by $20 \%(\mathrm{w} / \mathrm{w})$ pronase (Boehringer Mannheim, Mannheim, Germany) (treatment A). To release oligosaccharide chains, 0.2 units PNG-ase F from Flavobacterium meningosepticum (Boehringer Mannheim) was added to part of the pronase digests, and incubation carried out for $24 \mathrm{~h}$, with an addition of enzyme after $12 \mathrm{~h}$ of incubation (treatment B).

Concurrently, for the study of sulfated amino acids, portions of the pronase and PNG-ase $\mathrm{F}$ digests of $\left[{ }^{35}\right.$ S]sulfate-labeled thyroglobulin ( 100000 d.p.m.) were supplemented with $15 \mu \mathrm{g}$ serine-O-sulfate (Ser(S); Sigma, St Louis, MO, USA) and $15 \mu \mathrm{g}$ tyrosine-O-sulfate (Tyr(S)), prepared according to Reitz et al. (33), and submitted, for $48 \mathrm{~h}$ at $37^{\circ} \mathrm{C}$, to an extended digestion by 20\% (w/w) leucine aminopeptidase (LAP; cytosol type V from porcine kidney, Sigma).

\section{Concanavalin A affinity chromatography}

The thyroglobulin glycopeptides obtained after pronase digestion and the oligosaccharide chains released after pronase and subsequent PNG-ase $\mathrm{F}$ treatment were desalted on Bio-Gel P2 (Bio-Rad); then they were fractionated on a concanavalin $\mathrm{A}$-sepharose 4B (Pharmacia, Uppsala, Sweden) column as described previously (29). After the column had been washed with $25 \mathrm{ml}$ equilibrating buffer (ammonium bicarbonate buffer $0.05 \mathrm{~mol} / \mathrm{l}$, pH 8.0 containing $\mathrm{CaCl}_{2}$ (0.001 mol/l), $\quad \mathrm{MgCl}_{2} \quad(0.001 \mathrm{~mol} / \mathrm{l}), \quad$ and $\mathrm{NaCl}$ $(0.15 \mathrm{~mol} / \mathrm{l})$, it was eluted successively with $25 \mathrm{ml}$ $0.01 \mathrm{~mol} / \mathrm{l} \alpha$-methyl-glucoside (Sigma), and $25 \mathrm{ml}$ $0.5 \mathrm{~mol} / \mathrm{l} \alpha$-methyl-mannoside (Sigma) dissolved in the same buffer. Aliquots of each fractions were counted and the peaks were pooled and lyophilized.

\section{Alkaline hydrolysis}

Purified $\left[{ }^{35} \mathrm{~S}\right]$ sulfate-labeled thyroglobulin $(\sim 100 \mu \mathrm{g})$ from each culture condition was supplemented with $\operatorname{Tyr}(\mathrm{S})$ and $\operatorname{Ser}(\mathrm{S})(15 \mu \mathrm{g})$ and hydrolyzed with $100 \mu \mathrm{l}$ $0.2 \mathrm{~mol} / \mathrm{l}$ sodium hydroxide $(34)$ for $24 \mathrm{~h}$ at $110^{\circ} \mathrm{C}$ in glass vials sealed under a strictly nitrogenous atmosphere. The hydrolysis was stopped by cooling the samples at $+4{ }^{\circ} \mathrm{C}$.

\section{Cation-exchange chromatography}

Small columns of Dowex $50 \mathrm{WX} 2\left(\mathrm{H}^{+}\right.$form $)$were prepared as described elsewhere (33), with minor modifications. The cation-exchange resin was introduced in $1 \mathrm{ml}$ Gilson pipette tips closed with glass wool. The hydrolysates (enzymatic or alkaline) were acidified by an addition of $0.5 \mathrm{~mol} / \mathrm{l} \mathrm{HCOOH}$, and applied to the column. The non-retained material, containing the majority (85-90\%) of the radioactivity applied, corresponded to sulfated amino acids (in these conditions
$\operatorname{Tyr}(\mathrm{S})$ and $\operatorname{Ser}(\mathrm{S})$ were not retained), sulfated carbohydrates and inorganic sulfate. Fractions were collected, dried, and then analyzed by thin-layer chromatography.

\section{Thin-Iayer chromatography}

Thyroglobulin hydrolysates purified on Dowex 50WX2 were applied to silica-coated glass plates (Merck, Nogent-sur-marne, France) and thin-layer chromatography (TLC) was developed over a period of $4 \mathrm{~h}$, by means of an N-butylalcohol (Fluka Chemie, Buchs, Switzerland)-glacial acetic acid (Carlo Erba Reagenti, Milan, Italy)-water $(65: 20: 15)$ solvent system. Components were revealed by spraying a solution of $1 \%$ ninhydrin dissolved in acetone (Carlo Erba Reagenti).

\section{Quantitative determination of radioactivity}

The gels or the TLC plates were exposed to an imaging plate radioactive energy sensor (BAS-IP.MP 2040S, Fuji Photo Film Co. Ltd, Kanagawa, Japan) and were scanned (Fujix BAS1000 IP reader, Fuji). The radiolabeled thyroglobulin bands (on gels) or $\left[{ }^{35} \mathrm{~S}\right]$ sulfatelabeled spots (on TLC plates) were analyzed with the TINA 2.09 image program (Raytest Isotopenmeßgeräte $\mathrm{GmbH}$, Raytest SARL, Courbevoie, France). A reference curve of ${ }^{35} \mathrm{SO}_{4}{ }^{2-}$ was included in each exposure to calibrate the photostimulated luminescence in d.p.m. units. This procedure enabled us to calculate the specific radioactivity (d.p.m./pmol) of thyroglobulin and to demonstrate the distribution of the ${ }^{35}$ S] sulfate radioactivity within all the thyroglobulin components separated by TLC, expressed as a percentage of the total amount measured.

\section{Results}

\section{Regulation of the incorporation of sulfate residues into thyroglobulin: effects of TSH and iodide}

Porcine thyroid cells were cultured with or without TSH, and with or without iodide added daily to the basal medium. They were incubated with $\left[{ }^{35} \mathrm{~S}\right]$ sulfate for 4 days. We measured the incorporation of radioactive sulfate into thyroglobulin secreted into the apical media. In denaturing conditions, electrophoresis of the apical media showed essentially a band of thyroglobulin subunit $(330 \mathrm{kDa})$ revealed by Coomassie blue staining (Fig. 1A) and radioactivity (Fig. 1B). The amount of thyroglobulin secreted into the apical media by the cells stimulated by TSH was about fivefold greater than that secreted by unstimulated cells (Fig. 2a). Iodide decreased this TSH effect, as reported previously (30). The radioactivity of thyroglobulin bands was determined as described in Materials and methods. In the presence of $\mathrm{TSH}$, the $\left[{ }^{35} \mathrm{~S}\right]$ sulfate radioactivity 
associated with thyroglobulin was about twofold greater than that in the absence of TSH (Fig. 2b), but was decreased by the addition of iodide. However, the corresponding specific radioactivities (d.p.m./pmol) of thyroglobulin secreted by the cells stimulated by TSH were about twofold less than that for unstimulated cells $(-\mathrm{TSH} /+\mathrm{TSH}=2.4$ and $-\mathrm{TSH}+\mathrm{KI} /+\mathrm{TSH}+\mathrm{KI}=1.7$; Fig. 2c). Thus, in the presence of TSH, thyroglobulin incorporated about twofold less radioactive sulfate. A significant effect of iodide on the specific radioactivity appeared only in the presence of TSH:+TSH+KI/+TSH$\mathrm{KI}=1.4$. Different stages of thyroglobulin expression have been studied for their dependence on TSH, and the maximal responses were not obtained with the same concentration of hormone for each process (26). The usual concentration of TSH in that culture system was $100 \mu \mathrm{U} / \mathrm{ml}$, added to the basolateral side of the cells; at this concentration all the effects of TSH reached a plateau. We observed that the downregulation of thyroglobulin sulfation by the hormone was already maximal with a concentration of $25 \mu \mathrm{U} / \mathrm{ml} \mathrm{TSH}$, a nearly physiological dose (data not shown).

To investigate the role of TSH on the distribution of sulfate residues in the thyroglobulin molecule, we tried first to identify sulfated oligosaccharide chains and sulfated amino acids, in order to determine their relative content.
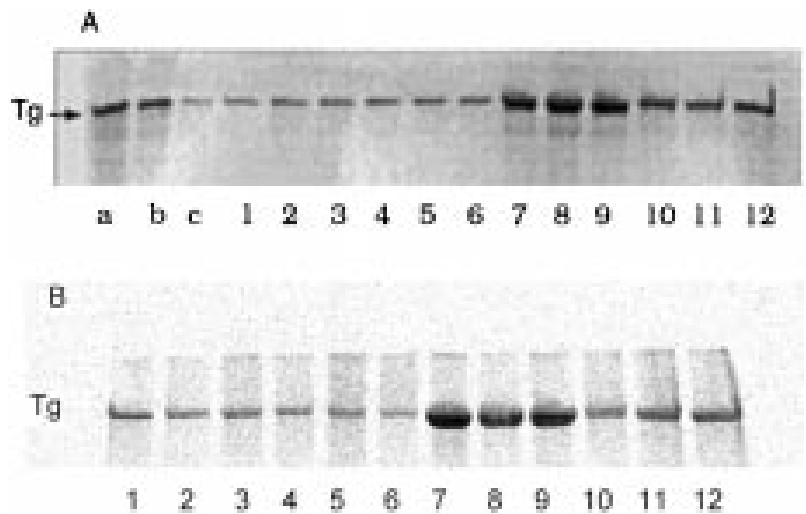

Figure 1 Identification of sulfated thyroglobulin $(\mathrm{Tg})$ in apical media. Thyroid cells were cultured with or without TSH $(100 \mu \mathrm{U} / \mathrm{ml})$ and with or without $\mathrm{KI}(0.5 \mu \mathrm{M})$ added daily to basal media, and labeled during 4 days with sulphur-35 $(70 \mu \mathrm{Ci} / \mathrm{ml})$. Apical media from cells cultured without TSH $(50 \mu \mathrm{l})$ and from cells cultured with TSH $(10 \mu \mathrm{l})$ were analyzed using 5\% (w/v) SDS-PAGE. (A) Gels stained with Coomassie blue; the band corresponds to the thyroglobulin subunit (330 kDa). Thyroglobulin standards purified from apical media of porcine cells cultured with TSH: $5 \mu \mathrm{g}, 3 \mu \mathrm{g}, 1 \mu \mathrm{g}$ (lanes a to c). Apical media from cells cultured without TSH and KI (lanes 1 to 3), cells cultured without TSH and with KI (lanes 4 to 6), cells cultured with TSH and without KI (lanes 7 to 9), and cells cultured with TSH and $\mathrm{KI}$ (lanes 10 to 12). (B) Gels exposed to an imaging plate radioactive energy sensor and then scanned in a Fujix BAS1000 IP reader. The radioactive band corresponds to sulfated thyroglobulin subunit (330 kDa). Culture conditions as in $(A)$.

\section{Distribution of $~_{35}^{35}$ S/sulfate-Iabeled glycopeptides and oligosaccharide chains on concanavalin $A$}

To investigate which carbohydrate units bear sulfate groups, glycopeptides and oligosaccharide chains of thyroglobulin (respectively obtained by pronase digestion and subsequent PNG-ase F treatment) were separated on concanavalin $\mathrm{A}$. The results are presented in Table 1. The major part of the radioactivity was associated with fractions, not retained on concanavalin
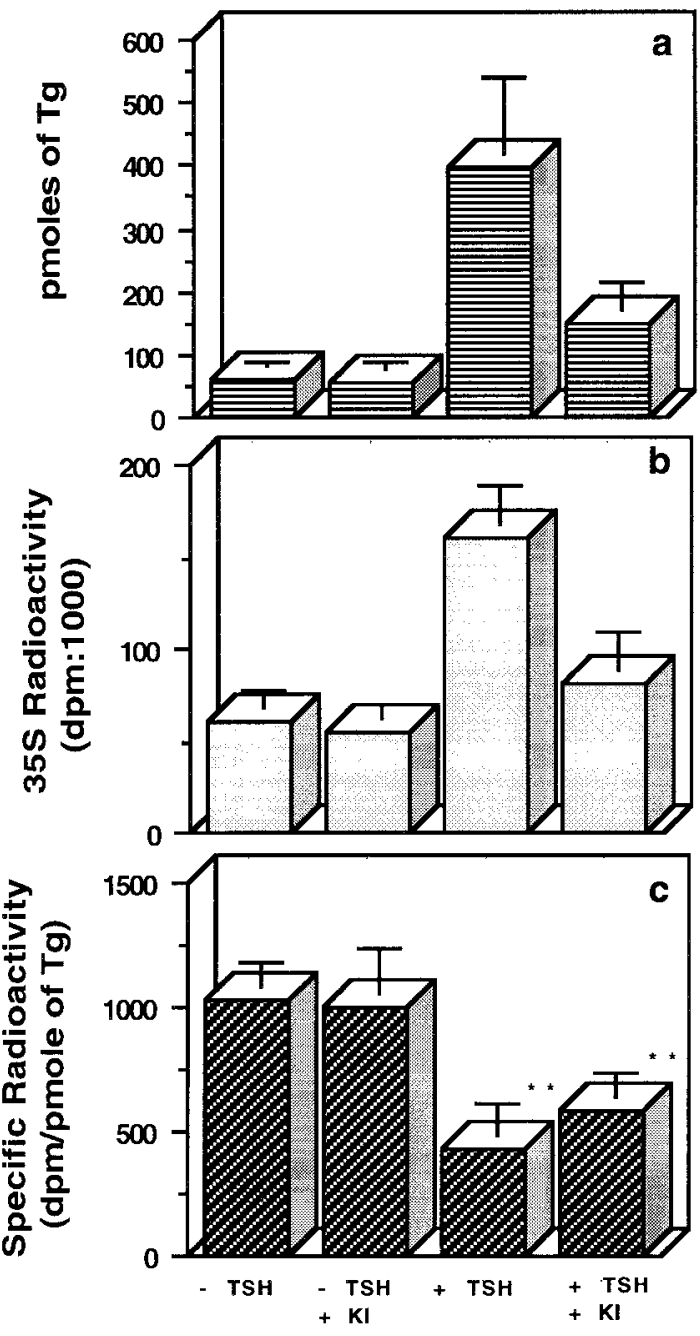

Figure 2 Determination of the specific radioactivity of thyroglobulin secreted into apical media of culture chambers. (a) Gels shown in Fig. 1A were scanned and analyzed by an image analyzing program. Apical thyroglobulin was determined quantitatively (pmol) by integration of peaks through a reference curve included in each analysis. (b) Radiolabeled thyroglobulin bands identified on gels (from Fig. 1B) were analyzed with the raytest TINA 2.09 program. A reference curve of ${ }^{35} \mathrm{SO}_{4}{ }^{2-}$ was included in each exposure to calibrate photostimulated luminescence in d.p.m. units. (c) Specific radioactivity (d.p.m./pmol thyroglobulin) calculated from data in (a) and $(b)$. Values are means \pm S.D. $(n=50)$; eight experiments. ${ }^{\star \star} P<0.01, t$-test. 
Table 1 Distribution on concanavalin A of $\left[{ }^{35}\right.$ S $]$ sulfate-labeled glycopeptides and oligosaccharide chains from apical thyroglobulin. Purified labeled thyroglobulin secreted into apical medium was digested by pronase (treatment A) or digested by pronase and PNG-ase F (treatment B) and analyzed on a concanavalin A column. The amount of radioactivity in each peak was expressed as a percentage of the total amount of radioactivity recovered. Values are means \pm S.D. $(n=3)$.

\begin{tabular}{|c|c|c|c|c|}
\hline & \multicolumn{4}{|c|}{ Radioactivity (\% of total) } \\
\hline & \multicolumn{2}{|c|}{ Treatment A } & \multicolumn{2}{|c|}{ Treatment B } \\
\hline & $-\mathrm{TSH}$ & $+\mathrm{TSH}$ & $-\mathrm{TSH}$ & $+\mathrm{TSH}$ \\
\hline $\begin{array}{l}\text { Run-through fractions } \\
\alpha \text {-Methyl-glucoside fractions } \\
\alpha \text {-Methyl-mannoside fractions }\end{array}$ & $\begin{array}{c}86.4 \pm 6.8 \\
13.5 \pm 6.9 \\
0\end{array}$ & $\begin{array}{c}85.8 \pm 5.8 \\
14.2 \pm 5.8 \\
0\end{array}$ & $\begin{array}{l}97.8 \pm 3.2 \\
2.2 \pm 0.35 \\
0\end{array}$ & $\begin{array}{c}97.6 \pm 3.7 \\
2.4 \pm 0.34 \\
0\end{array}$ \\
\hline
\end{tabular}

$-\mathrm{TSH},+\mathrm{TSH}$, cells respectively unstimulated or stimulated, with $\mathrm{TSH}$.

A, that contained glycopeptides bearing multiantennary oligosaccharide units and free amino acids or small peptides. No effect of TSH was observed on this distribution. After treatment with PNG-ase F (which cuts the Asn-GlcNAc bond), the proportion of radioactivity associated with biantennary units eluted with $\alpha$-methyl-glucoside became very low and had the same value for both unstimulated or TSH-stimulated cells. These observations suggest that PNG-ase F hydrolysis released sulfated amino acids or peptides probably

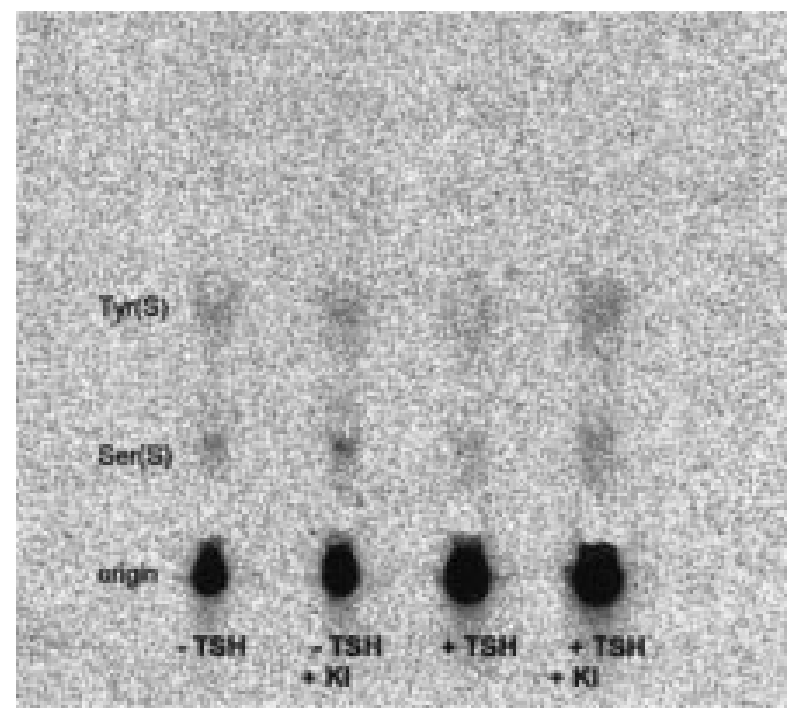

Figure 3 Identification of sulfated components released by enzymatic digestion of thyroglobulin and analyzed by TLC. Radiolabeled sulfated amino acids and other sulfated components released by extensive enzymatic digestions of thyroglobulin (pronase/PNG-ase F/LAP) as described in Materials and methods were separated by TLC on silica-coated glass plates along with unlabeled control sulfated amino acids $(\sim 15 \mu \mathrm{g})$. About 20000 to 40000 d.p.m. of radioactive material was used for each culture condition. $\operatorname{Tyr}(\mathrm{S})$ and $\operatorname{Ser}(\mathrm{S})$ were revealed by $1 \%$ ninhydrin staining. [ ${ }^{35}$ S]sulfate-labeled thyroglobulin components were identified by exposure to an imaging plate radioactive energy sensor and scanning in a Fujix BAS1000 IP reader. located near the asparagine-bearing biantennary units. In all cases, no radioactivity was bound to compounds eluted by $\alpha$-methyl-mannoside (polymannose moieties). Thus, relative to biantennary and polymannose units, multiantennary oligosaccharide units and peptide chain contain the major part of sulfate residues. To proceed with these studies to identify sulfated amino acids, it appeared necessary to use other techniques of analysis.

\section{Identification and distribution of thyroglobulin sulfated components on TLC}

Enzymatic (extensive treatment) or alkaline hydrolysates were purified by ion-exchange chromatography. TLC analysis of the run-through fractions showed that the major part of radioactivity from enzymatic hydrolysates did not migrate and represented essentially undigested compounds. Serine sulfate and tyrosine sulfate were present, but as traces (Fig. 3). No difference in the distribution of radioactivity was observed with TSH. As it has been suggested that the proportion of tyrosine sulfate is large (21), it appeared that the extensive enzymatic digestion used was not sufficient to achieve complete hydrolysis of dipeptides or tripeptides containing tyrosine sulfate. Consequently, thyroglobulins were submitted to an alkaline treatment known to allow the detection of tyrosine sulfate $(34,35)$.

We showed that tyrosine sulfate was a constituent of thyroglobulin secreted into the apical medium by cultured cells, and that serine sulfate remained in low amounts (Fig. 4A). The proportion of tyrosine sulfate was dramatically greater in the thyroglobulin secreted by unstimulated cells (Table 2). The radioactivity remaining at the origin corresponded to sulfate borne by oligosaccharide units, and the tail just beyond corresponded to released inorganic sulfate, identified by reference to the radiolabeled precursor developed on TLC (Fig. 4B); alkaline hydrolysis probably caused the desulfation of carbohydrates (35). Similar results were observed when enzymatic hydrolysates were submitted to an alkaline treatment. Thus the presence of TSH in 


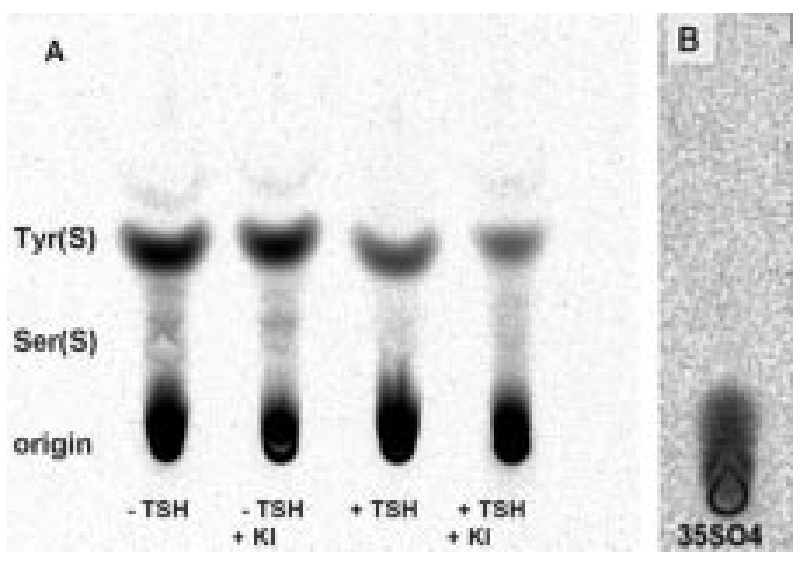

Figure 4 Identification of sulfated components after alkaline hydrolysis of thyroglobulin and analysis by TLC. (A) Akaline hydrolysates, purified, and separated by TLC: $\left[{ }^{35}\right.$ S]sulfate-labeled thyroglobulin components $(\operatorname{Tyr}(\mathrm{S})$ and $\operatorname{Ser}(\mathrm{S}))$ detected and analyzed as in Fig. 3. The band above $\operatorname{Tyr}(\mathrm{S})$ was identified as traces of $\left[{ }^{35}\right.$ S $]$ cysteine. (B) Standard for inorganic sulphur-35 identified as '[ $\left.{ }^{35} \mathrm{~S}\right]$ sulfate'.

the culture medium resulted in a decrease of the binding of sulfate to thyroglobulin, especially to tyrosine. A weak effect of iodide was observed on the proportion of tyrosine sulfate in TSH-stimulated cells (Fig. 4A, Table 2).

\section{Determination of the number of sulfate residues bound to thyroglobulin}

Concurrently, both the amount of intracellular inorganic sulfate and the free intracellular radioactivity were measured in each culture condition (36), in the same cells that secreted the thyroglobulin that was hydrolyzed and analyzed. The specific radioactivity of inorganic intracellular sulfate was deduced from these values (36). The number of residues bound to thyroglobulin secreted in the absence or presence of TSH and iodide was calculated (Table 3). The numbers of sulfate residues attached to amino acids and oligosaccharides were deduced (Table 3) from the distribution given in
Table 2. Thyroglobulin secreted in the presence of TSH contained 1.5-fold fewer sulfate residues; however, the number of tyrosine sulfate residues was sevenfold lower, whereas oligosaccharide units bore only 1.2-fold fewer sulfate residues. A slight effect of iodide appeared only in relation to the number of tyrosine sulfate residues.

\section{Discussion}

The effects of TSH and iodide on the sulfation of thyroglobulin were studied in porcine thyroid cells cultured on porous collagen-coated filters. We found that TSH decreased the binding of sulfate residues to thyroglobulin and controlled the quantitative distribution of sulfate residues between oligosaccharides and amino acids, and that, in the presence of TSH, there was a slight effect of iodide on the number of tyrosine sulfate residues.

Most of the sulfate residues were bound to multiantennary complex units of porcine thyroglobulin secreted by our cells, as we observed previously (29). Similar data have been reported for porcine, calf, and human thyroglobulin (16-18). We observed that, with TSH, oligosaccharide chains of porcine thyroglobulin bore 29 sulfate residues per mol thyroglobulin, probably bound to galactose and $\mathrm{N}$-acetylglucosamine residues. Human thyroglobulin contains 22 sulfate residues linked to galactose, besides those linked to $\mathrm{N}$-acetylglucosamine. Interestingly, by incubating thyroid slices with $\left[{ }^{35}\right.$ S $]$ sulfate, Spiro \& Spiro (17) found a distribution of sulfated oligosaccharides of calf thyroglobulin on concanavalin A that was close to the one we observed for porcine thyroglobulin; in both, about $90 \%$ of the radioactivity was associated with the complex oligosaccharide units. Taking into consideration that porcine thyroglobulin purified from thyroid gland contains about 18 complex oligosaccharide units per mol thyroglobulin $(37,38)$ we thus found about $1.5 \mathrm{~mol}$ sulfate $/ \mathrm{mol}$ complex oligosaccharide units. These values are close to data reported (16) for calf thyroglobulin $(1.6 \mathrm{~mol}$ sulfate/mol oligosaccharide complex units).

Table 2 Distribution on TLC of $\left.{ }^{35} \mathrm{~S}\right]$ sulfate radioactivity among thyroglobulin components after alkaline hydrolysis. The amount of radioactivity associated with each band in Fig. 4A was determined as described in Materials and methods. The distribution of radioactivity among the thyroglobulin components was expressed as a percentage of the total amount of radioactivity counted on the plate for each culture condition. Values are means \pm S.D. $(n=7)$, seven experiments.

\begin{tabular}{lcccc}
\hline \multicolumn{4}{c}{ Radioactivity $(\%$ of total) } \\
\cline { 2 - 5 } & $-\mathrm{TSH}$ & $-\mathrm{TSH}+\mathrm{KI}$ & $+\mathrm{TSH}$ & $+\mathrm{TSH}+\mathrm{KI}$ \\
\hline Tyrosine & $24.2 \pm 3.1$ & $24.3 \pm 5.6$ & $5.23 \pm 0.7$ & $7.07 \pm 1.1$ \\
Serine $^{55} \mathrm{SO}_{4}{ }^{2-}$ & $1.21 \pm 0.06$ & $1.21 \pm 0.2$ & $1.21 \pm 0.2$ & $1.21 \pm 0.27$ \\
& $74.06 \pm 3.4$ & $73.3 \pm 5.7$ & $93.2 \pm 1.4$ & $92.3 \pm 1.9$ \\
\hline
\end{tabular}

\footnotetext{
${ }^{35} \mathrm{SO}_{4}{ }^{2-}$, Inorganic sulfate resulting from desulfation of oligosaccharide units and undegraded
} sulfated oligosaccharide units. 
Table 3 Number of sulfate residues per mol thyroglobulin, bound to thyroglobulin (values are means \pm S.D; ( $n=10$ ) or bound to components (amino acids and complex oligosaccharides) of thyroglobulin (taking into account the percentages determined in Table 2). Numbers were determined by the ratio of the specific radioactivity of thyroglobulin (Fig. 2c) to the specific radioactivity of intracellular inorganic sulfate (data not presented).

\begin{tabular}{|c|c|c|c|c|c|c|}
\hline \multirow[b]{2}{*}{ Bound to } & \multicolumn{4}{|c|}{ Number of sulfate residues } & \multicolumn{2}{|c|}{ Ratios } \\
\hline & $-\mathrm{TSH}$ & $-\mathrm{TSH}+\mathrm{KI}$ & $+\mathrm{TSH}$ & $+\mathrm{TSH}+\mathrm{KI}$ & $-\mathrm{TSH} /+\mathrm{TSH}$ & $-\mathrm{TSH}+\mathrm{KI}+\mathrm{TSH}+\mathrm{KI}$ \\
\hline $\begin{array}{l}\text { Thyroglobulin } \\
\text { Components of } \\
\text { thyroglobulin }\end{array}$ & $45.81 \pm 6.29$ & $46.32 \pm 6.23$ & $30.65 \pm 4.99$ & $31.30 \pm 4.76$ & 1.5 & 1.5 \\
\hline Tyrosine & 11 & 11 & 1.6 & 2.2 & 6.9 & 5 \\
\hline $\begin{array}{l}\text { Serine } \\
\text { Complex }\end{array}$ & 0.6 & 0.6 & 0.4 & 0.4 & 1.5 & 1.5 \\
\hline oligosacch. & 34 & 34 & 29 & 29 & 1.2 & 1.2 \\
\hline
\end{tabular}

$-\mathrm{TSH},+\mathrm{TSH}$, cells respectively unstimulated or stimulated, with $\mathrm{TSH}$.

A controversy has emerged regarding the distribution of sulfate groups between oligosaccharide moieties and amino acid residues in thyroglobulin. After incubation of calf thyroid slices with radioactive sulfate, presence of tyrosine sulfate in thyroglobulin was not detected (17). When porcine follicles that had been turned inside out, were labeled with radioactive sulfate, in the presence of TSH, several sulfate residues were shown to be linked to tyrosine residues ( 9 per mol thyroglobulin), taking into account their sensitivity to acid hydrolysis (21). When our cells were cultured with TSH and iodide, we found 2 sulfated tyrosines per mol porcine thyroglobulin.

In our culture conditions, TSH downregulated the binding of sulfate residues to thyroglobulin, but the ratio of thyroglobulin from unstimulated cells to thyroglobulin from TSH-stimulated cells was different with respect to the specific radioactivity (ratio of 2) and the number of sulfated residues (ratio of 1.5). For the latter, the hormonal effect on the uptake, release, or both, of inorganic sulfate was not taken into account. This process is probably regulated by TSH, as was suggested (36) by the TSH effect on specific radioactivities of intracellular inorganic sulfate $(-\mathrm{TSH} /+\mathrm{TSH}=1.4)$. The weak effect of iodide on thyroglobulin sulfation observed only in the presence of TSH could be related to the hormonal regulation of intracellular concentration of the two anions.

TSH differently controls linking to oligosaccharide units and to amino acids. With TSH, the number of sulfate residues bound to carbohydrates was slightly lower than that of unstimulated cells (ratio of 1.2). In our previous results (29), we found a very similar ratio (1.3). A hormonal regulation of oligosaccharide sulfation has also been observed: thyrotropin-releasing hormone decreased the incorporation of radioactive sulfate in oligosaccharide moieties of the TSH molecule (39). Conversely, gonadotropin-releasing hormone increased the sulfation of oligosaccharide units of lutropin, as it up-regulated the incorporation of $\left[{ }^{3} \mathrm{H}\right]$ mannose (40). In porcine thyroid cells, the TSH control of thyroglobulin sulfation was more pronounced on tyrosine residues (ratio of 7) than on oligosaccharide units and serine residues (ratio of 1.5). Until now, the sulfation of tyrosine residues in thyroglobulin has not been considered to be dependent on hormonal regulation. TSH could act at different steps of thyroglobulin sulfation by modulating the level of different substrates and enzymes. The concentration of intracellular inorganic sulfate and of intermediate substrates (adenosine phosphosulfate and phosphoadenosine phosphosulfate (PAPS)), could influence the binding of sulfate residues. The capacity for sulfation is dependent either on the concentration of PAPS or on sulfotransferase activities (for review see (41)). The specificities of sulfotransferases have been pointed out; galactose- and tyrosyl-sulfotransferases might be differently regulated. Until now, there have been no studies of tyrosyl-sulfotransferase activity in the thyroid. The level of sulfotransferases could be controlled by TSH, as in glycosyltransferase expression (30, 42). Kato \& Spiro (43) characterized a galactose 3-Osulfotransferase in calf thyroid microsomes and suggested that it could compete with sialyl- and galactosyltransferases, as these last steps of thyroglobulin maturation occur in the Golgi apparatus. It is possible that TSH downregulates sulfotransferases, whereas it upregulates glycosyltransferases. Another hypothesis could explain alterations in thyroglobulin sulfation without TSH: the conformational structure of thyroglobulin synthesized by unstimulated cells is different because it is less glycosylated (29) and maybe more slowly transported (27), and consequently more sites could be available for sulfation.

As noted in the Introduction, there is little information on the role of sulfated residues in thyroglobulin metabolism. Sulfate groups linked to oligosaccharide chains or to tyrosine residues of thyroglobulin could take part in thyroglobulin-protein recognition, and could also have implications for the folding of the thyroglobulin molecule. Tyrosine sulfate is involved 
in activation-deactivation of biological activities of different proteins (6-9); the sulfated residues bound to tyrosines could be involved in hormonogenesis and the control of tyrosine sulfation of thyroglobulin by TSH could be related to this process. The presence of an acidic or neutral amino acid adjoining the amine side of tyrosine residue has been reported to be a necessary condition for tyrosine sulfation (44-46). Interestingly, most of the hormonogenic sites of thyroglobulin contain an acidic amino acid in position -1 of the tyrosine residues involved in the hormone (47), and the sequences of these sites were found to be strictly conserved in all species studied. Consequently, the tyrosine residue 'acceptor' could be a sulfated tyrosine. What role could the sulfate residue bound to tyrosine have in iodination or in the coupling reaction of iodotyrosines? Various hypotheses can be proposed. The sulfate group may act as an agent modifying the electronic environment of the aromatic ring of the tyrosine, which could become more reactive for iodination or coupling. The sulfate group could also be a recognition signal for the enzyme or the iodotyrosine 'donor'. Indeed, it was reported recently (48) that the presence of a sulfate group linked to the residue $\mathrm{Tyr}^{27}$ of cholecystokinin-A (CCK-A) allows an interaction of the aromatic ring of this tyrosine with the residue $\mathrm{Met}^{195}$ of the CCK-A receptor, to position the sulfate group correctly in the binding site of the receptor. This interaction is crucial for the transition of this receptor to a high-affinity state. Given that iodination takes place with unsulfated tyrosines by in vitro iodination with thyroperoxidase (49), and considering that the specificity of thyroglobulin is to allow the coupling of iodotyrosines and not tyrosine iodination, even in thyroid cells (50), we are inclined to believe that sulfate residues could act as a signal for coupling in vivo. This hypothesis would be in agreement with the fact that TSH controls the number of sulfated tyrosines, and with the observation that TSH modulates both the distribution of thyroid hormones among the known hormonogenic sites and the priority of their utilization (51). Consequently, $\mathrm{Tyr}^{5}$, the preferential hormonogenic site, could be part of the 2 sulfated tyrosine mols/mol thyroglobulin that we found. Recent results suggesting that the diiodotyrosine "inner ring' has the greatest influence on hormonogenesis (52) may support our hypothesis.

We observed a slight increase in carbohydrate sulfation in the absence of TSH. In human thyroid, some authors have observed an increased incorporation of $\left[{ }^{35} \mathrm{~S}\right]$ sulfate in the oligosaccharide units (complex and chondroitin sulfate) of human thyroglobulin derived from nodules as compared with normal tissue $(22,23)$. Recently, it was reported that gene mutations of a putative sulfate transporter occurred in Pendred syndrome (a congenital sensorineural hearing loss combined with a goiter), suggesting that sulfate metabolism could be linked to hormonogenesis (24). Other pathologies are associated with alterations in protein sulfation that could be, not only consequences of a pathology, but also intermediate modifications that serve to spread the disorder.

\section{Acknowledgements}

This work was supported by INSERM (U 38), CNRS (SDI 401038) and the Université de la Méditerranée. The authors thank Prof. P Carayon for reading the manuscript.

\section{References}

1 Baeuerle PA \& Huttner WB. Tyrosine sulfation is a trans-Golgispecific protein modification. Journal of Cell Biology 1987105 2655-2664.

2 Huttner WB. Tyrosine sulfation and the secretory pathway. Annual Review of Physiology 198850 363-376.

3 Hille A, Braulke T, von Figura K \& Huttner WB. Occurrence of tyrosine sulfate in proteins - a balance sheet. 1. Secretory and lysosomal proteins. European Journal of Biochemistry 1990188 577-586.

4 Hille A \& Huttner WB. Occurrence of tyrosine sulfate in proteins a balance sheet. 2. Membrane proteins. European Journal of Biochemistry 1990188 587-596.

5 Hooper LV, Manzella SM \& Baenziger JU. From legumes to leukocytes: biological roles for sulfated carbohydrates. FASEB Journal 199610 1137-1146.

6 Hortin GL, Farries TC, Graham JP \& Atkinson JP. Sulfation of tyrosine residues increases activity of the fourth component of complement. Proceedings of the National Academy of Sciences of the USA 198986 1338-1342.

7 Pittman DD, Wang JH \& Kaufman RJ. Identification and functional importance of tyrosine sulfate residues within recombinant factor VIII. Biochemistry 199231 3315-3325.

8 Dong JF, Li CQ \& Lopez JA. Tyrosine sulfation of the glycoprotein Ib-IX complex: identification of sulfated residues and effect on ligand binding. Biochemistry 199433 13946-13953.

9 Bundgaard JR, Vuust J \& Rehfeld JF. Tyrosine O-sulfation promotes proteolytic processing of progastrin. EMBO Journal 199514 3073-3079.

10 Yamori T, Kimura H, Stewart K, Ota DM, Cleary KR \& Irimura T. Differential production of high molecular weight sulfated glycoproteins in normal colonic mucosa, primary colon carcinoma, and metastases. Cancer Research 198747 27412747.

11 Liu MC \& Lipmann F. Decrease of tyrosine-O-sulfate-containing proteins found in rat fibroblasts infected with Rous sarcoma virus or Fujinami sarcoma virus. Proceedings of the National Academy of Sciences of the USA 198481 3695-3698.

12 Schick BP, Tang RP \& Jacoby JA. Changes in protein sulfation in human erythroleukemia (HEL), CHRF-288-11, and K562 cells following treatment with dimethyl sulfoxide or phorbol 12myristate 13-acetate. Archives of Biochemistry and Biophysics 1995 317 191-200.

13 Chace KV, Leahy DS, Martin R, Carubelli R, Flux M \& Sachdev GP. Respiratory mucous secretions in patients with cystic fibrosis: relationship between levels of highly sulfated mucin component and severity of the disease. Clinica Chimica Acta $1983132143-155$.

14 Wilson AP \& Rider CC. Evidence that leukosialin, CD43, is intensively sulfated in the murine T lymphoma line RDM-4. Journal of Immunology 1992148 1777-1783.

15 Baumeister FAM \& Herzog V. Sulfation of thyroglobulin: a ubiquitous modification in vertebrates. Cell and Tissue Research 1988252 349-358.

16 Spiro RG \& Bhoyroo VD. Occurrence of sulfate in the asparaginelinked complex carbohydrate units of thyroglobulin. Journal of Biological Chemistry 1988263 14351-14358. 
17 Spiro MJ \& Spiro RG. Biosynthesis of sulfated asparagine-linked complex carbohydrate units of calf thyroglobulin. Endocrinology $198812356-65$.

18 Schneider AB, McCurdy A, Chang T, Dudlak D \& Magner J. Metabolic labeling of human thyroglobulin with $\left[{ }^{35} \mathrm{~S}\right]$ sulfate: incorporation into chondroitin 6-sulfate and endoglycosidase-Fsusceptible carbohydrate units. Endocrinology $19881222428-$ 2435.

19 Kamerling JP, Rijkse I, Maas AAM, van Kuik JA \& Vliegenthart JFG. Sulfated $N$-linked carbohydrate chains in porcine thyroglobulin. FEBS Letters $1988241246-250$.

20 De Waard P, Koorevaar A, Kamerling JP \& Vliegenthart JFG. Structure determination by ${ }^{1} \mathrm{H}$ NMR spectroscopy of (sulfated) sialylated $N$-linked carbohydrate chains released from porcine thyroglobulin by peptide- $N^{4}$ - $(N$-acetyl- $\beta$-glucosaminyl)asparagine amidase-F. Journal of Biological Chemistry 19912664237 4243 .

21 Herzog V. Secretion of sulfated thyroglobulin. European Journal of Cell Biology 198539 399-409.

22 Schneider $\mathrm{AB} \&$ Dudlak D. Differential incorporation of sulfate into the chondroitin chain and complex carbohydrate chains of human thyroglobulin: studies in normal and neoplastic thyroid tissue. Endocrinology 1989124 356-362.

23 Sakurai S, Fogelfeld L, Ries A \& Schneider AB. Anionic complexcarbohydrate units of human thyroglobulin. Endocrinology 1990 127 2056-2063.

24 Everett LA, Glaser B, Beck JC, Idol JR, Buchs A, Heyman M, Adawi F, Hazani E, Nassir E, Baxevanis AD, Sheffield VC \& Green ED. Pendred syndrome is caused by mutations in a putative sulphate transporter gene (PDS). Nature Genetics 199717411 422 .

25 Chambard M, Mauchamp J \& Chabaud O. Synthesis and apical and basolateral secretion of thyroglobulin by thyroid cell monolayers on permeable substrate: modulation by TSH. Journal of Cellular Physiology 1987133 37-45.

26 Chabaud O, Chambard M, Gaudry N \& Mauchamp J. Thyrotrophin and cyclic AMP regulation of thyroglobulin gene expression in cultured porcine thyroid cells. Journal of Endocrinology 1988 $11625-33$.

27 Chambard M, Depetris D, Gruffat D, Gonzalvez S, Mauchamp J \& Chabaud O. Thyrotrophin regulation of apical and basal exocytosis of thyroglobulin by porcine thyroid monolayers. Journal of Molecular Endocrinology 19904 193-199.

28 Desruisseau S, Alquier C, Depetris D, Gruffat D \& Chabaud O. Hormonal regulation of some steps of thyroglobulin synthesis and secretion in bicameral cell culture. Journal of Cellular Physiology $1994160336-334$

29 Desruisseau-Gonzalvez S, Franc JL, Gruffat D \& Chabaud O. Glycosylation of thyroglobulin secreted by porcine cells cultured in chamber system: thyrotropin controls the number of oligosaccharides and their anionic residues. Endocrinology 1994134 1676-1684.

30 Desruisseau S, Valette A, Franc JL \& Chabaud O. Thyrotropin controls dolichol-linked sugar pools and oligosaccharyltransferase activity in thyroid cells. Molecular and Cellular Endocrinology 1996 $122223-228$.

31 Gruffat D, Venot N, Marriq C \& Chabaud O. Thyroid hormone synthesis in thyroglobulin secreted by porcine thyroid cells cultured on porous bottom chambers. Effect of iodide. Endocrinology $19921312921-2927$.

32 Laemmli U. Cleavage of structural protein during the assembly of the head of bacteriophage T4. Nature 1970227 680-685.

33 Reitz HC, Ferrel RE, Fraenkel-Conrat H \& Olcott HS. Action of sulfating agents on proteins and model substances. I. Concentrated sulfuric acid. Journal of American Chemical Society 194668 1024-1031.

34 Blode H, Heinrich T \& Diringer, H. A quantitative assay for tyrosine sulfation and tyrosine phosphorylation in peptides. Biological Chemistry Hoppe-Seyler 1990371 145-151.
35 Huttner WB. Determination and occurrence of tyrosine $O$-sulfate in proteins. Methods in Enzymology 1984107 200-223.

36 Cauvi D, Venot N, Nlend MC \& Chabaud O. Regulations of intracellular inorganic sulfate. Relation with thyroglobulin sulfation. Journal of Endocrinological Investigation 199821 (Suppl) 28.

37 Fukuda M \& Egami F. Isolation and fractionation of glycopeptides from porcine thyroglobulin. Biochemical Journal $1971123407-$ 414.

38 Franc JL, Mallet B, Lanet I \& Giraud A. The number of oligosaccharides borne by porcine thyroglobulin is variable. Endocrinology $1994134885-900$.

39 Gesundheit N, Magner JA, Chen T \& Weintraub BD. Differential sulfation and sialylation of secreted mouse thyrotropin (TSH) subunits: regulation by TSH-releasing hormone. Endocrinology $1986119455-463$.

40 Sardanons ML, Solano AR \& Podesta EJ. Gonadotropin-releasing hormone action upon luteinizing hormone bioactivity in pituitary gland: role of sulfation. Journal of Biological Chemistry 1987262 11149-11155.

41 Klaassen CD \& Boles JW. Sulfation and sulfotransferases 5: the importance of $3^{\prime}$-phosphoadenosine $5^{\prime}$-phosphosulfate (PAPS) in the regulation of sulfation. FASEB Journal $199711404-418$.

42 Franc JL, Hovsepian S, Fayet G \& Bouchilloux S. Differential effects of thyrotropin on various glycosyltransferases in porcine thyroid cells. Biochemical Biophysical Research Commnications 1984118 910-915.

43 Kato Y \& Spiro RG. Characterization of a thyroid sulfotransferase responsible for the 3-O-sulfation of selection of terminal beta-Dgalactosyl residues in N-linked carbohydrate units. Journal of Biological Chemistry $19892643364-3371$.

44 Hortin GL, Folz R, Gordon JI \& Strauss AW. Characterization of sites of tyrosine sulfation in proteins and criteria for predicting their occurrence. Biochemical and Biophysical Research Communications $1986141326-333$.

45 Niehrs C, Beisswanger R \& Huttner WB. Protein tyrosine sulfation 1993 - an update. Chemico-Biological Interactions 199492 257271.

46 Bundgaard JR, Vuust J \& Rehfeld JF. New consensus features for tyrosine $O$-sulfation determined by mutational analysis. Journal of Biological Chemistry 1997272 21700-21705.

47 Malthièry Y, Marriq C, Bergé-Lefranc JL, Franc JL, Henry M, Lejeune PJ, Ruf J \& Lissitzky S. Thyroglobulin structure and function: recent advances. Biochimie 198971 195-210.

48 Gigoux V, Escrieu C, Silvente-Poirot S, Maigret B, Gouilleux L, Fehrentz JA, Gully D, Moroder L, Vaysse N \& Fourny D. Met-195 of the cholecytokinin-A receptor interacts with the sulfated tyrosine of cholecystokinin and is crucial for receptor transition to high affinity state. Journal of Biological Chemistry 1998273 1438014386.

49 Coval ML, \& Taurog A. Purification and iodinating activity of hog thyroid peroxydase. Journal of Biological Chemistry 1967242 5510-5523.

50 Lemansky P, Popp GM, Tietz J \& Herzog V. Identification of iodinated proteins in cultured thyrocytes and their possible significance for thyroid hormone formation. Endocrinology 1994 135 1566-1575.

51 Fassler CA, Dunn JT, Anderson PC, Fox JW, Dunn AD, Hite LA, Moore RC \& Kim PS. Thyrotropin alters the utilization of thyroglobulin's hormonogenic sites. Journal of Biological Chemistry $198826317366-17371$.

52 De Vijlder JJM \& den Hartog MT. Anionic iodotyrosine residues are required for iodothyronine synthesis. European Journal of Endocrinology $1998138227-231$.

Received 26 October 1998

Accepted 25 March 1999 